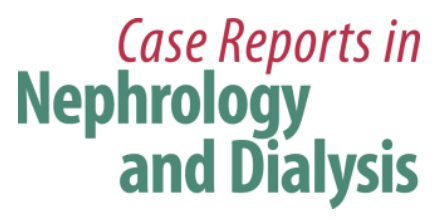

\title{
Exercise-Induced Acute Kidney Injury in a Police Officer with Hereditary Renal Hypouricemia
}

\author{
Yoshio Shimizu a, beiichi Wakabayashia Ayako Totsuka ${ }^{a, d}$ \\ Yoko Hayashi $^{a}$ Shusaku Nitta ${ }^{a}$ Kazuaki Hara ${ }^{a}$ Maiko Akira ${ }^{a}$ \\ Yasuhiko Tominoc ${ }^{c}$ Yusuke Suzuki ${ }^{d}$ \\ aDivision of Nephrology, Department of Internal Medicine, Juntendo University Shizuoka \\ Hospital, Izunokuni, Japan; 'Shizuoka Medical Research Center for Disaster, Juntendo \\ University, Tokyo, Japan; 'Asian Pacific Renal Research Promotion Office, Showakai \\ Medical Corporation, Tokyo, Japan; dDivision of Nephrology, Department of Internal \\ Medicine, Faculty of Medicine, Juntendo University, Tokyo, Japan
}

\section{Keywords}

Exercise $\cdot$ Acute kidney injury $\cdot$ Hereditary renal hypouricemia $\cdot$ Police officer

\begin{abstract}
Hereditary renal hypouricemia is characterized by hypouricemia with hyper-uric acid clearance due to a defect in renal tubular transport. Patients with hereditary renal hypouricemia have a higher risk of exercise-induced acute kidney injury (EAKI) and reduced kidney function. Although the best preventive measure is avoiding exercise, there are many kinds of jobs that require occupational exercise. A 27-year-old male police officer suffered from stage $3 \mathrm{AKI}$ after performing a 20-m multistage shuttle run test. His mother had previously been diagnosed as having renal hypouricemia at another facility. The patient had reported having hypouricemia during a health check at a previous police station, but his serum uric acid concentration was within the normal range at our hospital. After treatment, he recovered from EAKI and exhibited
\end{abstract}



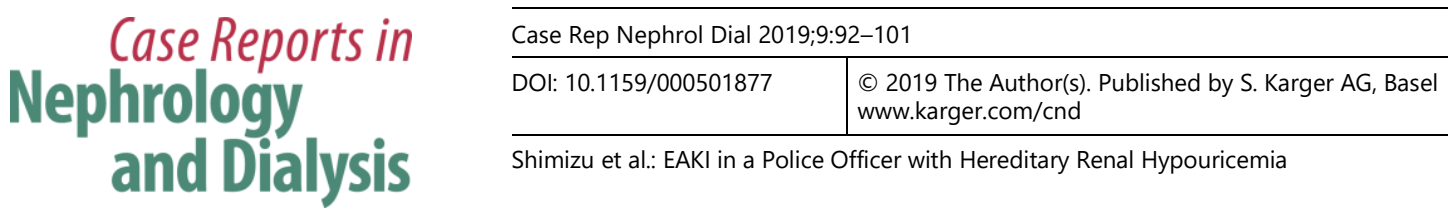

low serum uric acid and hyper-uric acid clearance. Since the patient desired to continue his career requiring strenuous exercise, it was difficult to establish a preventive plan against the recurrence of EAKI. Patients with hereditary renal hypouricemia who must undergo strenuous occupational anaerobic exercise are at higher risk of developing EAKI than other workers. The risks of EAKI among patients with hypouricemia should be considered when undergoing physical occupational training.

(C) 2019 The Author(s)

Published by S. Karger AG, Basel

\section{Introduction}

Hereditary renal hypouricemia is an autosomal recessive disease characterized by hypouricemia with hyper-uric acid clearance. This disease is divided into two groups, based on the presence of mutations in the SLC22A12 gene. Type 1 is caused by a loss-of-function mutation in the SLC22A12 gene encoding the urate transporter 1 (URAT1) [1]. Type 2 is derived from defects in the SLC2A9 gene encoding the glucose transporter 9 (GLUT9) [2] (Fig. 1).

While most patients are asymptomatic, episodes of the urolithiasis and exercise-induced acute kidney injury (EAKI) are sometimes observed [3,4]. The increased risk of urolithiasis is due to hyperuricosuria and hypercalciuria [5]. Furthermore, the pathogenesis of EAKI remains unclear. Acute uric acid nephropathy as a consequence of the increased production of uric acid during exercise-induced ATP degradation, and vasoconstriction and ischemia in response to oxidative stress from oxygen-free radicals have been proposed as causes of the renal injury $[3,6]$. It has been speculated that severe hypouricemia increases the risk of reduced kidney function through antioxidant potential, since uric acid is one of the most important antioxidants in human plasma [7, 8].

Since past AKI episodes have been closely related to the development of chronic kidney disease, the prevention of recurrent EAKI is crucial for patients with hereditary renal hypouricemia [9]. Although the most effective approach to prevention is avoiding anaerobic exercise, many kinds of jobs require physical activities. Herein, we present a case of a young EAKI patient with hereditary renal hypouricemia who worked as a police officer. It was difficult to develop a preventive plan for his return to work. Although the number of reports of EAKI in hereditary renal hypouricemia patients are increasing, job-related EAKI and its prevention have been rarely discussed.

\section{Case Report}

A 27-year-old male was referred to our hospital by a family doctor due to nausea, headache, low back pain, and elevated serum creatinine. The patient was a police officer working in a regional police station. He noted the symptoms after a 20 -m multistage shuttle run test as part of his occupational physical training. In brief, this test consisted of continuous running back and forth between two lines, $20 \mathrm{~m}$ apart, within a given time interval. The participants had to keep running between the two lines and turning when signaled by the beeps. The time was shortened every minute, increasing the speed by $0.5 \mathrm{~km} / \mathrm{h}$ from a starting speed of 8.5 


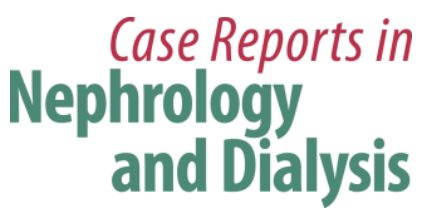

Case Rep Nephrol Dial 2019;9:92-101

DOI: $10.1159 / 000501877$

(c) 2019 The Author(s). Published by S. Karger AG, Base www.karger.com/cnd

Shimizu et al.: EAKI in a Police Officer with Hereditary Renal Hypouricemia

km/h. (Fig. 2). [10]. The patient had exhibited no serious illnesses except for usual childhood diseases until adulthood. He only consumed alcohol on social occasions - up to a bottle of beer. He was not a smoker. His mother was diagnosed as having renal hypouricemia and his grandmother had died from renal failure. The mother's serum uric acid concentration was maintained below $2.0 \mathrm{mg} / \mathrm{dL}$. Laboratory data could not be obtained from the other family members. The patient was reported to exhibit hypouricemia during a regular medical checkup.

The patient was of average build and well nourished but appeared to be in some discomfort. There were no significant abnormalities on physical examination. Urinalysis showed a \pm dipstick test for protein and negative for sugar. The urinary protein-to-creatinine ratio was $0.22 \mathrm{~g} / \mathrm{g}$ creatinine. Laboratory tests revealed a serum urea nitrogen of $50.9 \mathrm{mg} / \mathrm{dL}$ (normal values: 9-21), creatinine level of $4.89 \mathrm{mg} / \mathrm{dL}(0.4-0.9)$ and eGFR of $13.3 \mathrm{~mL} / \mathrm{min} / 1.73 \mathrm{~m}^{2}$, indicating stage 3 AKI (KDIGO). The hematologic evaluation, biological tests including creatine phosphokinase and uric acid, and serological tests were all within normal ranges (Table 1). Abdominal computed tomography (CT) scan revealed no morphological abnormalities in the kidneys and urinary tracts (Fig. 3).

Since the fractional excretion of sodium was $0.4 \%$, we diagnosed pre-renal AKI due to volume depletion after exercise. We performed drip infusion and ordered the patient to rest and avoid strenuous physical activities. One month later, the urinary findings and renal function returned to normal. The serum uric acid was $0.5 \mathrm{mg} / \mathrm{dL}$ and fractional excretion of uric acid was $82 \%$, suggesting that he was also exhibiting renal hypouricemia and that this episode was due to EAKI in hereditary renal hypouricemia [4].

The patient and his family strongly desired for him to keep his career. While the best way for the patient to avoid the recurrence of AKI was to avoid anaerobic exercise, he had to return to physical training. We advised him to drink a sufficient volume of water before and after the exercise and to stop training as soon as he experienced nausea or back pain. We also explained the patient's risk of AKI to his director and requested that arrangements be made to control the nature and level of exercise. Since then, he has been able to manage his risk and there have been no further episodes of AKI.

\section{Discussion}

The incidence of hypouricemia in Japan has been reported to be $0.12-0.19 \%[11,12]$, and hypouricemia is associated with reduced kidney function [7]. Hypouricemia is also associated with a history of kidney disease, especially in males [12]. It is considered that these phenomena are caused by recurrent EAKI and urinary stones [12].

Many jobs, such as police officers, soldiers, and professional athletes, require strenuous physical exercise. Japanese police officers have to maintain and improve their physical abilities pre- and post-employment [13]. Their physical abilities are subsequently checked at regular intervals [14]. The 20-m shuttle run test, which triggered EAKI in our patient, is included among the evaluation items [14]. While the 20-m shuttle run test was designed to measure aerobic fitness by predicting the maximum oxygen uptake and performance, it is known that the test is a better predictor for running performance and optimal training intensity $[15,16]$. The score is likely influenced by anaerobic power and capacity [16]. Every police officer must undergo regular health checks. While serum uric acid is regularly measured as part of the 


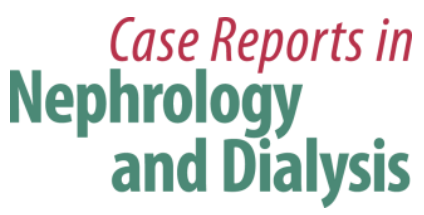

Case Rep Nephrol Dial 2019;9:92-101

DOI: $10.1159 / 000501877$

(c) 2019 The Author(s). Published by S. Karger AG, Base www.karger.com/cnd

Shimizu et al.: EAKI in a Police Officer with Hereditary Renal Hypouricemia

health check, hypouricemia at a younger age tends to be missed since its aim is mainly to differentiate those who have hyperuricemia among the middle-aged and elderly.

The most critical point was for our patient to maintain his career without recurrence of EAKI. In addition to our patient, there have been two reports of EAKI in a Japanese sumo wrestler and a professional cyclist $[17,18]$. The 18-year-old Japanese sumo wrestler was advised to warm up before exercise and he subsequently did not experience any similar episodes, even though the hypouricemia (0.8-1.0 mg/dL) persisted; however, the "warm up" method was not described in detail [17]. Renal blood flow does not change significantly after mild exercise compared with at rest [19], and low-volume sprint exercise increases plasma catalase activity, one of the antioxidative enzymes [20]. Long-term regular moderate exercise training shifts the redox balance towards a reducing environment [21]. An 18-year-old professional trainee cyclist with EAKI was diagnosed as having "acute renal failure with severe loin pain and patchy renal ischemia after anaerobic exercise" (ALPE) [18]. Although 51\% of ALPE cases have been reported to involve patients with renal hypouricemia, his serum uric acid was within the normal range [22]. This trainee was told to avoid physical exercise when he was sick, dehydrated, or taking medications, and he ultimately made his debut as a professional cyclist and continued his career without relapse for more than 3 years [18]. We advised our patient to consume a sufficient volume of fluids before and after exercise, since his fractional excretion of sodium was below $1 \%$, indicating that volume depletion played a key role in the $\mathrm{AKI}$, and to discontinue exercise when he felt nausea or low back pain, as observed in this episode. Although prevention of the recurrence of EAKI was favored, further prophylaxis was advised to be considered if he underwent relapse. Allopurinol, which inhibits uric acid production, would be one candidate. It has been shown that administration of $300 \mathrm{mg}$ allopurinol to 5 renal hypouricemia patients prevented EAKI, as well as exercise-induced increases in uric acid excretion [23]. The rationale for the use of allopurinol in hypouricemic patients is to decrease the generation of uric acid and filtered uric acid load during exercise [23]. Moreover, allopurinol also exhibits an antioxidant property through the inhibition of xanthine oxidase, an important biological source of free radicals [24].

Although the patient's hypouricemia had been reported previously and the patient's mother had been diagnosed as having hereditary hypouricemia, he did not know the risk of EAKI. If the patient's risk had been shared with the doctor who had diagnosed his mother as well as the doctor managing the health check in the police, this episode could have been avoided.

It was difficult to make the patient's director accommodate his exercise regimen since the relationship between EAKI and hereditary renal hypouricemia have not been well established in the community. It is beneficial to inform people that serum uric acid levels are risk markers of gout (at high levels) as well as EAKI (at low levels), especially when physical activity is required. When we diagnosed the patient as having EAKI, the clinical presentation strikingly suggested ALPE [25]. It was preferable to perform contrast media-enhanced CT, in order to identify severe vasoconstriction in the kidneys as wedge-shaped defects. Since he had stage 3 AKI (KDIGO), we did not attempt to perform enhanced CT and selected the term "EAKI" [4, 25].

Recent studies have shown that elevated uric acid is not only an indicator of cardiovascular and kidney disease, but also a true indicator or mediator of the etiology [8]. Based upon clinical and experimental data, uric acid appears to play a dual role, with both pro- and 

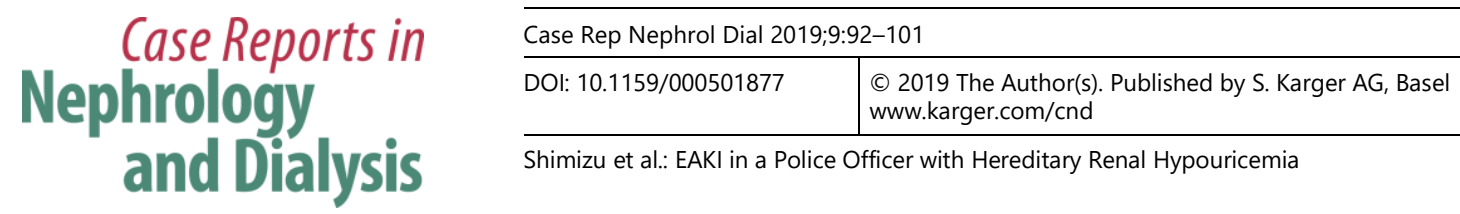

Shimizu et al.: EAKI in a Police Officer with Hereditary Renal Hypouricemia

antioxidant activities [8]. Intracellular uric acid generally imposes harmful effects, as a prooxidant, in cultured cells and in animal models of hyperuricemia, supported by the protective effects of an inhibitor of the organic anion transporter, which blocks the entry of uric acid into the cells, and the amelioration of oxidative stress [26]. On the other hand, according to a hypothesis by Ames et al. [27], silencing of the uricase gene with increased serum uric acid levels in humans provided an evolutional advantage for our ancestors. This hypothesis is based upon the findings of in vitro studies demonstrating uric acid as a powerful scavenger of free radicals and as a chelator of transitional metal ions in sera [27]. The paradoxical roles of uric acid are possibly regulated in different compartments of the body [8]. Thus, it is suggested that hypouricemia directly connects to the loss of antioxidant activity, leading to vascular and renal damage $[7,8,28]$ (Fig. 4).

\section{Conclusion}

Patients with hereditary renal hypouricemia who are required to be engaged in occupational exercise have a higher risk of EAKI than other workers. Serum uric acid levels should be focused on at both higher and lower values compared with the normal range. It is necessary to consider the risks and the design of any preventive plan for EAKI.

\section{Acknowledgments}

We are indebted to the nephrologists, the nursing staff, and the patient at Juntendo University Shizuoka Hospital for their collaboration and participation in this study.

\section{Statement of Ethics}

This study was approved by the Ethics Committee of the Juntendo University Shizuoka Hospital. Written informed consent was obtained from the patient.

\section{Disclosure Statement}

The authors have no conflicts of interest to declare.

\section{Funding Sources}

This study was supported by the Japan Society for the Promotion of Science (JSPS) KAKENHI (grant No. 26461238 and 17K09039). The Shizuoka Medical Research Center for Disaster, Juntendo University, is supported by the MEXT-Supported Program for the Strategic Research Foundation at Private Universities, 2015-2019. 


\section{Author Contributions}

Y.S., K.W., T.A., T.H., S.N., M.A., and K.H. were responsible for the clinical management of the patient and for preparing the draft version of this manuscript. Y.T. and Y.S. contributed to the review of the literature. All authors participated in the writing of the manuscript and read and approved the final version.

\section{References}

1 Ichida K, Hosoyamada M, Hisatome I, Enomoto A, Hikita M, Endou H, et al. Clinical and molecular analysis of patients with renal hypouricemia in Japan-influence of URAT1 gene on urinary urate excretion. J Am Soc Nephrol. 2004 Jan;15(1):164-73.

2 Dinour D, Gray NK, Campbell S, Shu X, Sawyer L, Richardson W, et al. Homozygous SLC2A9 mutations cause severe renal hypouricemia. J Am Soc Nephrol. 2010 Jan;21(1):64-72.

3 Nishizaki N, Fujinaga S, Hirano D, Kanai H, Kaya H, Ohtomo Y, et al. Hereditary renal hypouricemia: a cause of calcium oxalate urolithiasis in a young female. Clin Nephrol. 2012 Feb;77(2):161-3.

4 Yan MT, Cheng CJ, Chen JS, Lin SH. The case: a young man with acute kidney injury after exercise. The diagnosis: exercise induced acute kidney injury in hereditary renal hypouricemia. Kidney Int. 2010 May;77(10):935-6.

5 Fujinaga S, Ito A, Nakagawa M, Watanabe T, Ohtomo Y, Shimizu T. Posterior reversible encephalopathy syndrome with exercise-induced acute kidney injury in renal hypouricemia type 1. Eur J Pediatr. 2013 Nov;172(11):1557-60.

6 Ohta T, Sakano T, Igarashi T, Itami N, Ogawa T; ARF Assocoated with Renal Hypouricemia Research Group. Exercise-induced acute renal failure associated with renal hypouricaemia: results of a questionnaire-based survey in Japan. Nephrol Dial Transplant. 2004 Jun;19(6):1447-53.

7 Wakasugi M, Kazama JJ, Narita I, Konta T, Fujimoto S, Iseki K, et al. Association between hypouricemia and reduced kidney function: a cross-sectional population-based study in Japan. Am J Nephrol. 2015;41(2):13846.

8 Kang DH, Ha SK. Uric Acid Puzzle: Dual Role as Anti-oxidantand Pro-oxidant. Electrolyte Blood Press. 2014 Jun;12(1):1-6.

9 Belayev LY, Palevsky PM. The link between acute kidney injury and chronic kidney disease. Curr Opin Nephrol Hypertens. 2014 Mar;23(2):149-54.

10 Léger LA, Mercier D, Gadoury C, Lambert J. The multistage 20 metre shuttle run test for aerobic fitness. J Sports Sci. 1988;6(2):93-101.

11 Igarashi T, Sekine T, Sugimura H, Hayakawa H, Arayama T. Acute renal failure after exercise in a child with renal hypouricaemia. Pediatr Nephrol. 1993 Jun;7(3):292-3.

12 Kuwabara M, Niwa K, Ohtahara A, Hamada T, Miyazaki S, Mizuta E, et al. Prevalence and complications of hypouricemia in a general population: A large-scale cross-sectional study in Japan. PLoS One. 2017 Apr;12(4):e0176055.

13 National Police Agency. Police of Japan 2017. Overview of Japanese Police. Available from: http://www.npa.go.jp/english/POJcontents.html.

14 Shizuoka Prefectural Police. Japan Police Physical Activity Test (JAPPAT). Japanese. Available from: https://www.pref.shizuoka.jp/police/about/hore/kunre/documents/keimu005.pdf\#search=\%27JAPpAT+ $\%$ E9\%9D\%99\%E5\%B2\%A1\%27.

15 Léger LA, Lambert J. A maximal multistage 20-m shuttle run test to predict VO2 max. Eur J Appl Physiol Occup Physiol. 1982;49(1):1-12.

16 Paradisis GP, Zacharogiannis E, Mandila D, Smirtiotou A, Argeitaki P, Cooke CB. Multi-Stage 20-m Shuttle Run Fitness Test, Maximal Oxygen Uptake and Velocity at Maximal Oxygen Uptake. J Hum Kinet. 2014 Jul;41(1):81-7.

17 Mima A, Ichida K, Matsubara T, Kanamori H, Inui E, Tanaka M, et al. Acute renal failure after exercise in a Japanese sumo wrestler with renal hypouricemia. Am J Med Sci. 2008 Dec;336(6):512-4.

18 Shimizu Y, Takaori K, Maeda S. Exercise-induced acute renal failure in a trainee cyclist without hypouricemia: successful athletic career post-treatment. J Gen Fam Med. 2017 Aug;18(6):432-5. 


\section{Case Reports in Nephrology and Dialysis}

\begin{tabular}{l|l}
\hline Case Rep Nephrol Dial 2019;9:92-101 \\
\hline DOI: 10.1159/000501877 & $\begin{array}{l}\text { @ } 2019 \text { The Author(s). Published by S. Karger AG, Basel } \\
\text { www.karger.com/cnd }\end{array}$ \\
\hline
\end{tabular}

Shimizu et al.: EAKI in a Police Officer with Hereditary Renal Hypouricemia

19 Kawakami S, Yasuno T, Matsuda T, Fujimi K, Ito A, Yoshimura S, et al. Association between exercise intensity and renal blood flow evaluated using ultrasound echo. Clin Exp Nephrol. 2018 Oct;22(5):1061-8.

20 Parker L, Trewin A, Levinger I, Shaw CS, Stepto NK. Exercise-intensity dependent alterations in plasma redox status do not reflect skeletal muscle redox-sensitive protein signaling. J Sci Med Sport. 2018 Apr;21(4):416-21.

21 Seifi-Skishahr F, Damirchi A, Farjaminezhad M, Babaei P. Physical Training Status Determines Oxidative Stress and Redox Changes in Response to an Acute Aerobic Exercise. Biochem Res Int. 2016;2016:3757623.

22 Ishikawa I. Acute renal failure with severe loin pain and patchy renal ischemia after anaerobic exercise in patients with or without renal hypouricemia. Nephron. 2002 Aug;91(4):559-70.

23 Yeun JY, Hasbargen JA. Renal hypouricemia: prevention of exercise-induced acute renal failure and a review of the literature. Am J Kidney Dis. 1995 Jun;25(6):937-46.

24 Alem MM. Allopurinol and endothelial function: A systematic review with meta-analysis of randomized controlled trials. Cardiovasc Ther. 2018 Aug;36(4):e12432.

25 Ishikawa I. Comments on 'a young man with acute kidney injury after exercise'. Kidney Int. 2010 Nov;78(10):1047-8.

26 Kang DH, Park SK, Lee IK, Johnson RJ. Uric acid-induced C-reactive protein expression: implication on cell proliferation and nitric oxide production of human vascular cells. J Am Soc Nephrol. 2005 Dec;16(12):355362.

27 Ames BN, Cathcart R, Schwiers E, Hochstein P. Uric acid provides an antioxidant defense in humans against oxidant- and radical-caused aging and cancer: a hypothesis. Proc Natl Acad Sci USA. 1981 Nov;78(11):685862.

28 Celermajer DS. Endothelial dysfunction: does it matter? Is it reversible? J Am Coll Cardiol. 1997 Aug;30(2):325-33.

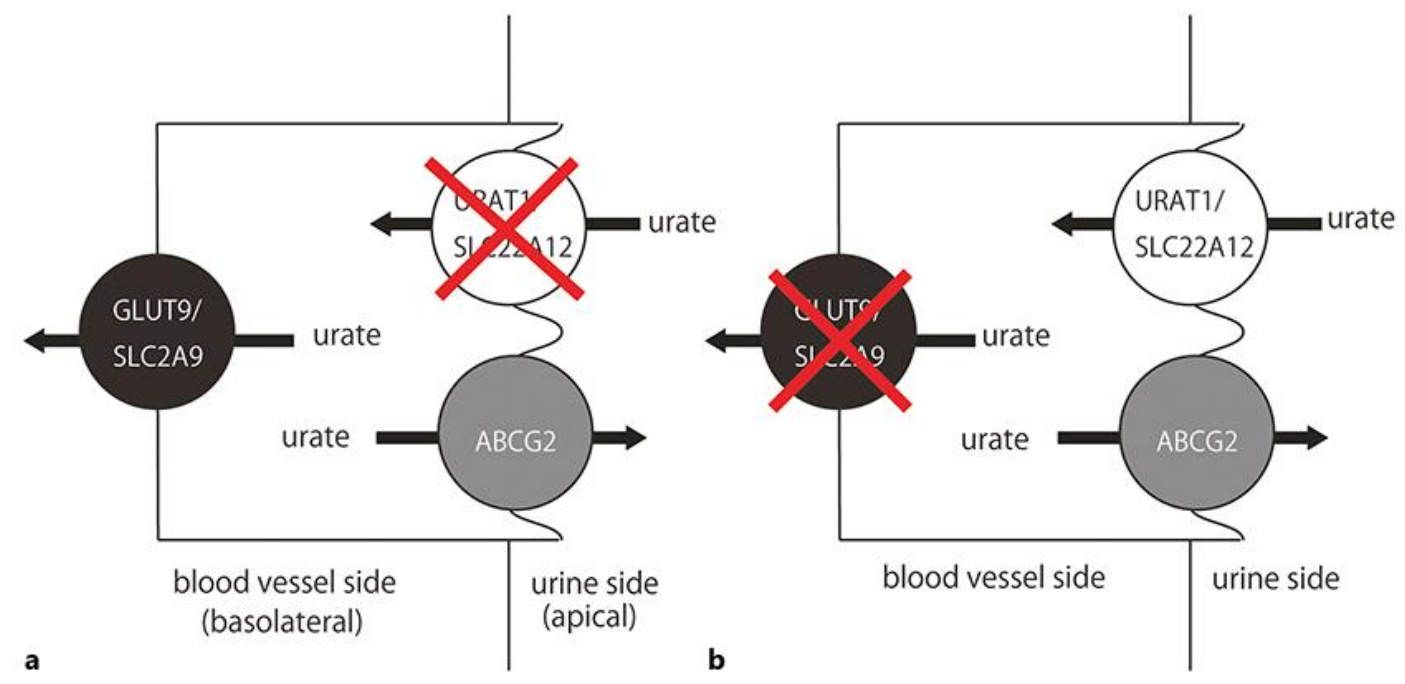

Fig. 1. Pathophysiological model of renal hypouricemia at the proximal tubules. a Pathophysiological model of renal hypouricemia type 1 . b Pathophysiological model of renal hypouricemia type 2 . 


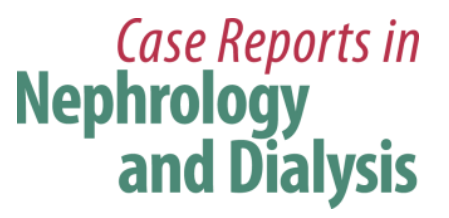

Case Rep Nephrol Dial 2019;9:92-101

DOI: $10.1159 / 000501877$

(c) 2019 The Author(s). Published by S. Karger AG, Basel
www.karger.com/cnd

Shimizu et al.: EAKI in a Police Officer with Hereditary Renal Hypouricemia

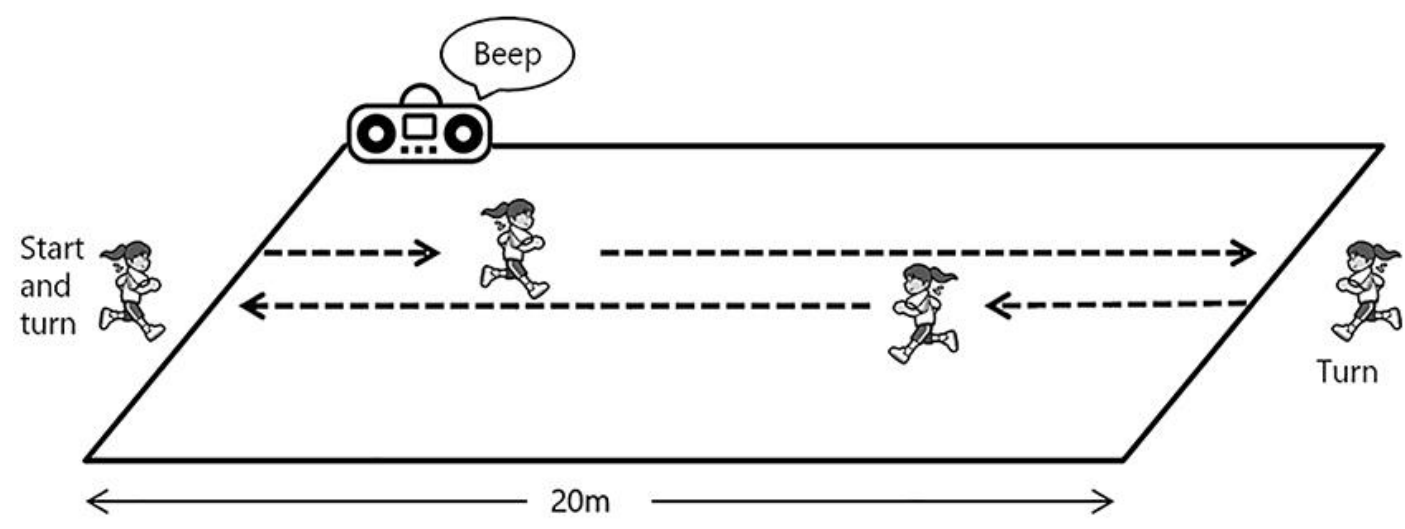

Fig. 2. The 20-m multistage shuttle run test. The participant continues to run back and forth between two lines, $20 \mathrm{~m}$ apart, within the interval of the beeps and has to increase the running speed gradually.

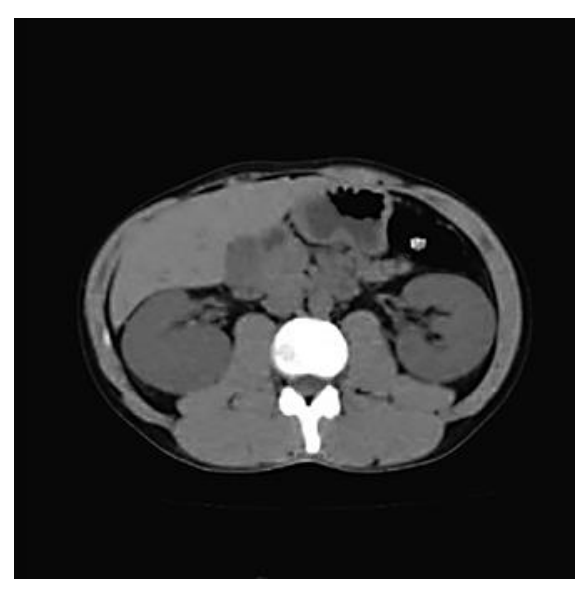

Fig. 3. Abdominal CT image of the patient (non-enhanced). CT image of the patient shows no evidence of urolithiasis or hydronephrosis. The size and shape of both kidneys are normal. 


\section{Case Reports in Nephrology and Dialysis}

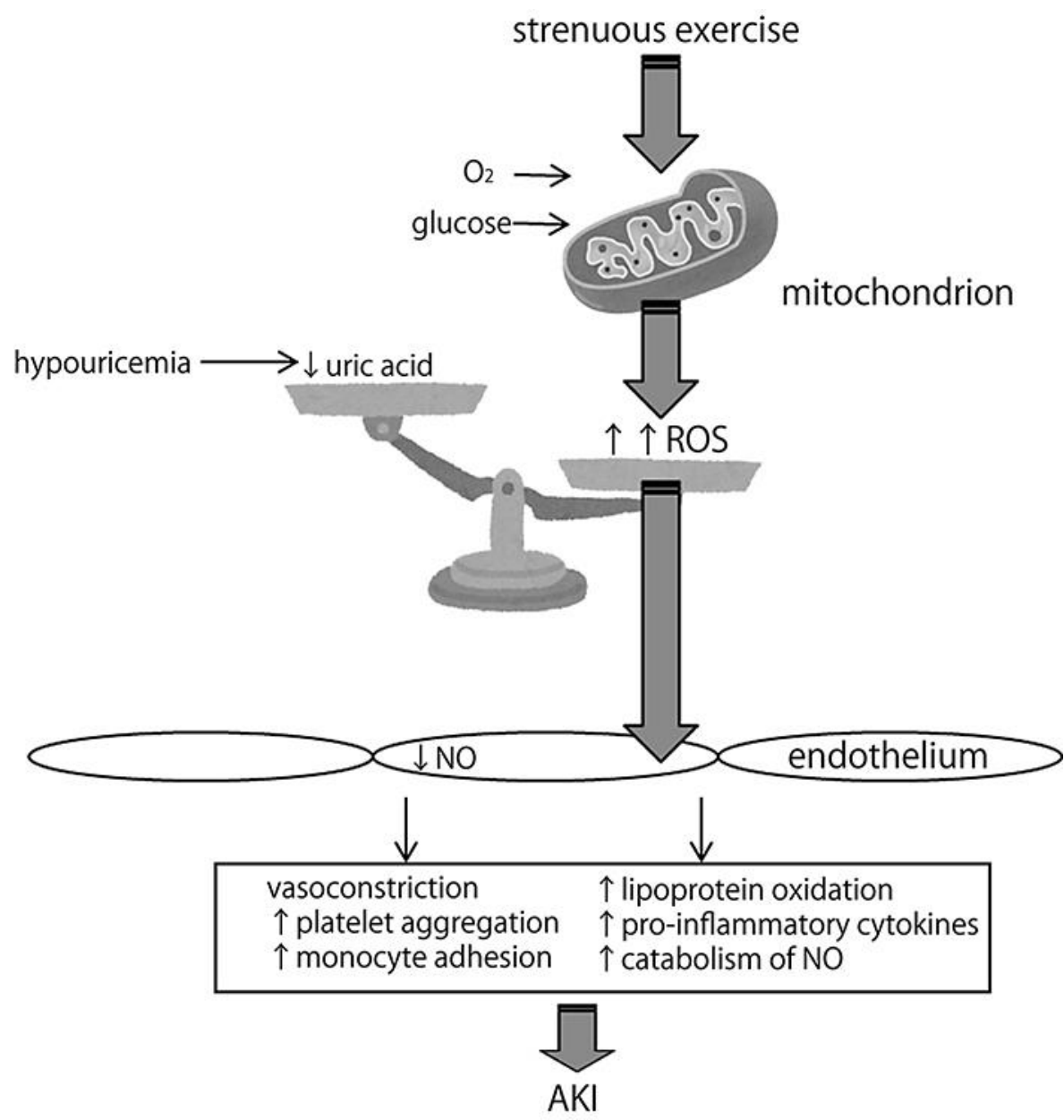

Fig. 4. Putative pathogenesis of EAKI. Strenuous exercise induces massive reactive oxygen species (ROS) which overcomes anti-oxidative activity of uric acid. Vascular constriction and endothelial damages play a key role in the development of AKI. 


\section{Case Reports in Nephrology and Dialysis}

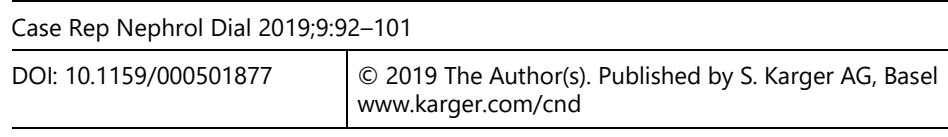

Shimizu et al.: EAKI in a Police Officer with Hereditary Renal Hypouricemia

Table 1. Results of the laboratory tests

\begin{tabular}{|c|c|c|c|c|c|c|c|}
\hline Urinalysis & $\begin{array}{l}\text { First } \\
\text { visit }\end{array}$ & $\begin{array}{l}1 \text { month } \\
\text { later }\end{array}$ & Normal range & Chemistry & First visit & $\begin{array}{l}1 \text { month } \\
\text { later }\end{array}$ & $\begin{array}{l}\text { Normal } \\
\text { range }\end{array}$ \\
\hline SG & 1.008 & 1.014 & $1.015-1.025$ & $\mathrm{TP}, \mathrm{g} / \mathrm{dL}$ & 7 & nd & $6.3-7.8$ \\
\hline $\mathrm{pH}$ & 5.5 & 7 & $5.0-7.8$ & Alb, g/dL & 4.2 & nd & $3.7-4.9$ \\
\hline Protein & $( \pm)$ & $(-)$ & $(-)$ & AST, IU/L & 11 & 16 & $11-40$ \\
\hline Occult blood & $(-)$ & $(-)$ & $(-)$ & ALT, IU/L & 7 & 14 & $6-43$ \\
\hline Glucose & $(-)$ & $(-)$ & $(-)$ & LDH, IU/L & 152 & 169 & $200-400$ \\
\hline $\mathrm{RBC}, n / \mathrm{HPF}$ & $<1$ & $<1$ & $<1$ & $\mathrm{CK}, \mathrm{IU} / \mathrm{L}$ & 62 & 77 & $57-197$ \\
\hline \multirow[t]{2}{*}{ WBC, $n / \mathrm{HPF}$} & $1-4$ & $<1$ & $<1-3$ & BUN, mg/dL & 50.9 & 13.6 & $9-21$ \\
\hline & & & & $\mathrm{Cr}, \mathrm{mg} / \mathrm{dL}$ & 4.89 & 0.79 & $0.4-0.9$ \\
\hline Hyaline casts, $n / \mathrm{WF}$ & $(-)$ & $(-)$ & $<1-2$ & $\mathrm{eGFR}, \mathrm{mL} / \mathrm{min} / 1.73 \mathrm{~m}^{2}$ & 13.3 & 97.5 & $>60$ \\
\hline Granular casts, & $(-)$ & $(-)$ & $(-)$ & $\mathrm{UA}, \mathrm{mg} / \mathrm{dL}$ & 2.8 & 0.5 & $3.8-7.5$ \\
\hline Protein, g/gCr & 0.22 & 0 & $<0.05$ & $\mathrm{Na}, \mathrm{mEq} / \mathrm{L}$ & 139 & 143 & $135-145$ \\
\hline NAG, IU/L & 8.2 & nd & $0.7-11.2$ & $\mathrm{~K}, \mathrm{mEq} / \mathrm{L}$ & 4.2 & 4.2 & $3.5-4.9$ \\
\hline \multirow[t]{2}{*}{$\beta_{2}-$ microglobulin, $\mu \mathrm{g} / \mathrm{L}$} & 487 & nd & $<230$ & $\mathrm{Cl}, \mathrm{mEq} / \mathrm{L}$ & 102 & 106 & $96-108$ \\
\hline & & & & $\mathrm{Ca}, \mathrm{mg} / \mathrm{dL}$ & 9.7 & nd & $8.5-10.5$ \\
\hline Peripheral blood & & & & $\mathrm{P}, \mathrm{mg} / \mathrm{dL}$ & 4.3 & nd & $2.5-4.5$ \\
\hline $\mathrm{WBC}, n / \mu \mathrm{L}$ & 5,400 & 5,700 & $4700-8700$ & $\mathrm{CRP}, \mathrm{mg} / \mathrm{dL}$ & 1.1 & nd & $<0.5$ \\
\hline $\mathrm{RBC}, \times 10^{4} / \mu \mathrm{L}$ & 455 & 445 & $427-500$ & HbA1c, \% & 5.1 & nd & $<5.8$ \\
\hline $\mathrm{Hb}, \mathrm{g} / \mathrm{dL}$ & 14 & 13.8 & $13.5-17.6$ & FT3, pg/mL & 2.1 & nd & $2.2-4.3$ \\
\hline $\mathrm{Ht}, \%$ & 42 & 40.3 & $39.8-51.8$ & FT4, ng/mL & 1.2 & nd & $0.8-1.6$ \\
\hline \multirow[t]{2}{*}{ PLT, $\times 10^{4} / \mu \mathrm{L}$} & 22.9 & 23.6 & $15-35$ & $\mathrm{TSH}, \mu \mathrm{IU} / \mathrm{mL}$ & 1.34 & nd & $0.2-4.5$ \\
\hline & & & & $\mathrm{BNP}, \mathrm{pg} / \mathrm{mL}$ & 38.8 & nd & $<18.4$ \\
\hline Serology & & & & Fractional excretion & & & \\
\hline ANA & $320 \mathrm{X}$ & nd & $(-)$ & & Admission & $\begin{array}{l}1 \text { month } \\
\text { later }\end{array}$ & \\
\hline IgG, mg/dL & 1,092 & nd & 739-1649 & $\mathrm{Na}, \%$ & 0.4 & 1.1 & \\
\hline IgA, mg/dL & 184 & nd & $107-363$ & UN, \% & 36 & 38 & \\
\hline IgM, mg/dL & 240 & nd & $46-260$ & UA, $\%$ & nd & 82 & \\
\hline $\mathrm{C} 3, \mathrm{mg} / \mathrm{dL}$ & 84.9 & nd & $65-135$ & & & & \\
\hline $\mathrm{C} 4, \mathrm{mg} / \mathrm{dL}$ & 28.5 & nd & $13-35$ & & & & \\
\hline $\mathrm{CH} 50, \mathrm{U} / \mathrm{mL}$ & 45 & nd & $28-53$ & & & & \\
\hline Cryoglobulin & $(-)$ & nd & $(-)$ & & & & \\
\hline MPO-ANCA, EU & $<10$ & nd & $<10$ & & & & \\
\hline PR3-ANCA, EU & $<10$ & nd & $<10$ & & & & \\
\hline
\end{tabular}

nd, not done. 